\title{
PERANCANGAN ULANG MACHINING FIXTURE UNTUK PRODUK CYLINDER HEAD DAN COVER CRANKCASE TIPE 168
}

\author{
Asep Indra Komara ${ }^{1}$, Robby Ray Rinaldy ${ }^{2}$ \\ ${ }^{1}$ Teknologi Rekayasa Perancangan Manufaktur, Politeknik Manufaktur Bandung \\ ${ }^{2}$ Teknologi Rekayasa Manufaktur, Konsentrasi Teknik Rekayasa dan Pengembangan Produk \\ Jalan Kanayakan No.21 Dago-Bandung 40135, Phone/Fax : (022) 2500241/(022)2502649 \\ asep.indra@polman-bandung.ac.id
}

\begin{abstract}
Abstrak
Cylinder head dan cover crankcase adalah komponen dari sebuah engine yang diproduksi oleh sebuah perusahaan manufaktur. Perusahaan perlu melakukan perbaikan pada proses produksi komponen-komponen tersebut agar dapat bersaing dengan kompetitor mereka. Perbaikan proses produksi dilakukan dengan cara memperbaiki tahapan proses pemesinan dan perancangan ulang fixture produk engine tersebut. Sebenarnya perusahaan sudah memiliki fixture untuk proses pemesinan engine tersebut, namun fixture belum bisa digunakan untuk memproduksi komponen engine karena masih belum berfungsi secara baik. Permasalahan yang terjadi adalah adanya penyimpangan dimensi hasil pemesinan dan kurang efektifnya proses pemesinan sehingga mengurangi produktivitas kerja. Maka dari itu, perlu dirancang fixture baru yang mampu menjawab kedua permasalahan tersebut. Perancangan fixture melalui penerapan metode VDI 2222 yang dikombinasikan dengan metode perancangan menurut Handbook of Jig Fixture telah menghasilkan rancangan fixture dan estimasi waktu proses pemesinan baru untuk komponen engine. Rancangan fixture selanjutnya dianalisis dan divalidasi mengunakan software rekayasa untuk memastikan kemampuan rigiditas fixture terhadap gaya pencekaman, gaya pemesinan, serta defleksi yang terjadi saat proses pemesinan yang dapat berdampak pada penyimpangan dimensi. Berdasar pada hasil kajian yang dilakukan, maka telah dihasilkan rancangan fixture untuk pemesinan produk cylinder head dan cover crankcase dengan dimensi fixture 450 x 459 x 1125 dengan berat $190 \mathrm{~kg}$. Waktu yang dibutuhkan untuk menyelesaikan produk cylinder head sebesar 308,67 detik dan cover crankcase sebesar 224,19 detik. Gaya pencekaman maksimum yang dibutuhkan sebesar $0,36 \mathrm{kN}$. Defleksi yang terjadi pada batang pencekam sebesar $0,0048 \mathrm{~mm}$, pada rangka fixture sebesar $0,029 \mathrm{~mm}$ dan deformasi pada produk sebesar $0,06 \mathrm{~mm}$. Rancangan fixture diharapkan telah mampu menyelesaikan permasalahan yang ada di perusahaan saat ini.
\end{abstract}

Kata kunci: perancangan, fixture, pemesinan, engine.

\begin{abstract}
The cylinder head and crankcase cover are components of an engine produced by a manufacturing company in Tangerang. Companies need to make improvements to the production process of these components in order to compete with their competitors. The improvement of the production process is done by improving the machining process stages and re-designing the engine product fixture. Actually, the company already has a fixture for the engine machining process, but the fixture cannot be used to produce engine components because it still does not function properly. The problem that occurs is the deviation of the dimensions of machining results and the ineffectiveness of the machining process thereby reducing work productivity. Therefore, it is necessary to design a new fixture that is able to answer both of these problems. Fixture design through the application of the VDI 2222 method combined with the design method according to the Handbook of Jig Fixture has resulted in a fixture design and estimated new machining process time for engine components. The fixture design is then analyzed and validated using engineering software to ensure the fixture's rigidity of the clamping force, machining force, and deflection that occur during the machining process which can have an impact on dimensional deviations. Based on the results of the study conducted, a fixture design for machining cylinder head and crankcase cover products has been produced with fixture dimensions of $450 \times 459 \times 1125$ with a weight of $190 \mathrm{~kg}$. The time needed to complete the cylinder head product is 308.67 seconds and the crankcase cover is 224.19 seconds. The maximum clamping force required is $0.36 \mathrm{kN}$. Deflection that occurs in the clamping rod is $0.0048 \mathrm{~mm}$, the fixture frame is $0.029 \mathrm{~mm}$ and the product deformation is $0.06 \mathrm{~mm}$. The fixture design is expected to be able to solve the problems that exist in the company today.
\end{abstract}

1 Komara, Asep Indra., dkk; Perancangan Ulang Machining Fixture Untuk Produk Cylinder Head Dan Cover Crankcase Tipe 168 
Key words : design, fixture, machining, engine.

\section{PENDAHULUAN}

Salah satu komponen utama pada produk Air Compressor ialah engine penggerak, yang berfungsi untuk menghasilkan hisapan dan menghasilkan udara bertekanan yang selanjutnya dialirkan ke dalam tangki separator. Engine penggerak terdiri dari beberapa komponen diantaranya crankcase engine, cylinder head dan cover crankcase. Komponenkomponen ini merupakan hasil dari proses teknologi die casting. Komponen engine tersebut mengalami proses pemesinan menggunakan mesin CNC Milling dengan bantuan sebuah fixture.

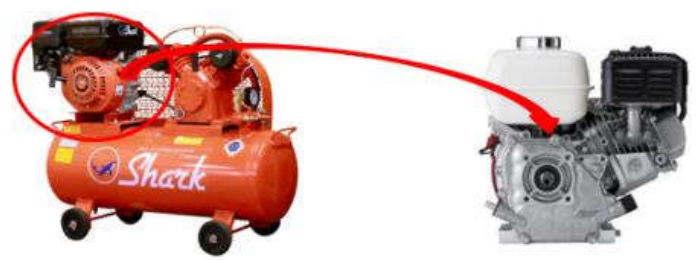

\section{Gambar 1 Kompressor dan Engine Shark}

Komponen-komponen tersebut di proses pemesinan dengan menggunakan bantuan dua buah fixture. Pada fixture-1 komponen yang di proses pemesinan adalah satu produk crankcase engine (CE) dan satu produk cover crankcase (CC). Pada fixture2 komponen yang diproses pemesinan adalah satu produk crankcase engine (CE) dan dua produk cylinder head $(\mathrm{CH})$. Layout dapat dilihat pada gambar 2 dan gambar 3 berikut:

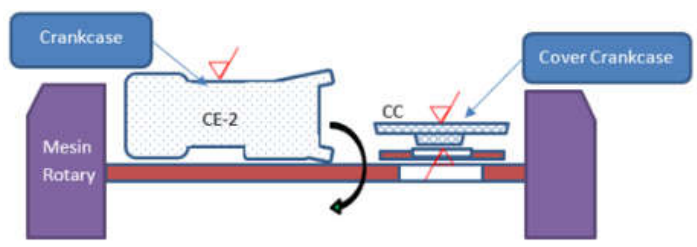

Gambar 2 Layout eksisting fixture-1

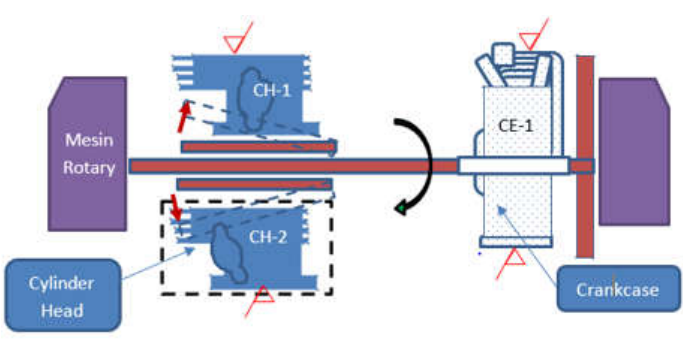

Gambar 3 Layout eksisting fixture-2
Kedua fixture eksisting masih terkendala pada dimensi hasil produk yang menyimpang, toleransi tidak tercapai, dan ketidakefektifan layout proses sehingga tidak produktif. Oleh karena itu, diperlukan perancangan ulang fixture dan menganalisis kemungkinan penyebab terjadinya kegagalan fixture untuk produk komponen engine yang mampu mengatasi permasalahan yang tersebut. Berdasarkan kajian perusahaan dan hasil diskusi yang dilakukan, diputuskan untuk melakukan perancangan fixture baru untuk produk Cylinder Head dan Cover Crankcase.

\section{METODE PENELITIAN}

Proses perancangan ulang fixture dilakukan mengacu pada metode VDI 2222 seperti pada [1], yang dikombinasikan dengan metode perancangan menurut [2] dengan skema urutan sebagai berikut.

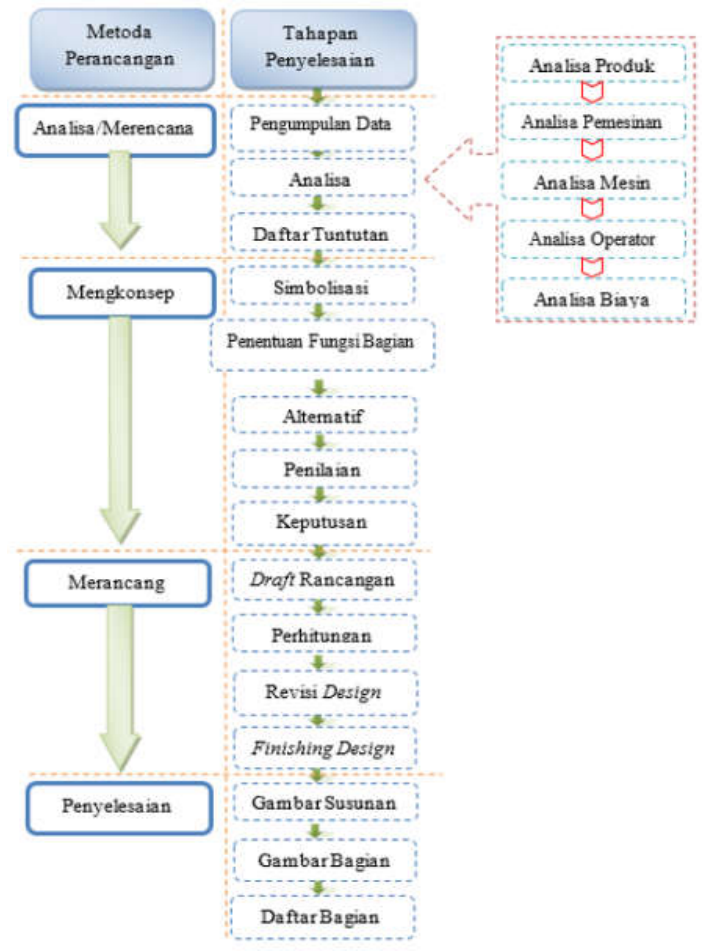

\section{Gambar 4 Diagram Alir Perancangan}

Pada tahap merencana fixture, langkah pertama adalah mengumpulkan data dan menyusun

2 Komara, Asep Indra., dkk; Perancangan Ulang Machining Fixture Untuk Produk Cylinder Head Dan Cover Crankcase Tipe 168 
daftar tuntutan. Aktivitas penting pada tahap ini adalah melakukan analisis produk, analisis proses pemesinan, analisis mesin dan analisis pengoperasian seperti pada [2]. Hasil penting dari analisis produk adalah ditetapkannya tahapan proses pemesinan yang akan dilakukan untuk menghasilkan produk sesuai dengan tuntutan pada gambar kerja produk. Pada tahap mengkonsep, desain fixture dikembangkan dengan mengunakan simbolisasi rancangan fixture untuk mempermudah penetapan setiap fungsi bagian dari fixture. Selanjutnya dilakukan pemilihan komponen yang mampu memenuhi fungsi dari simbolisasi yang telah ditetapkan pada tahap perancangan.

\section{HASIL DAN PEMBAHASAN}

Fixture yang dirancang diharapkan dapat mempercepat proses tanpa mengurangi aspek kualitas produk. Kondisi yang perlu dipertimbangkan adalah biaya, detail, dan pengoperasian tooling [3] hal 11 . Berikut daftar tuntutan yang telah disusun:

Tabel 1 Parameter proses pemesinan drill

\begin{tabular}{|c|c|c|c|}
\hline No & & $\overline{\text { Daftar Tuntutan }}$ & Keterangan \\
\hline \multirow[t]{6}{*}{1} & \multicolumn{3}{|c|}{ Tuntutan Primer } \\
\hline & A & Mesin yang digunakan & CNC Brother S700X1 \\
\hline & $\mathrm{B}$ & Dimensi Fixture Max & $\leq 800 \mathrm{~mm} \times 400 \mathrm{~mm} \times 480 \mathrm{~mm}$ \\
\hline & $\mathrm{C}$ & Berat Maksimal Fixture & $250 \mathrm{~kg}$ \\
\hline & $\mathrm{D}$ & Waktu Pemesinan & 5 menit/produk \\
\hline & $\mathrm{D}$ & Mesin Pemutar & Yukiwa YNCP 200 \\
\hline \multirow[t]{3}{*}{2} & \multicolumn{3}{|c|}{ Tuntutan Sekunder } \\
\hline & A & $\begin{array}{l}\text { Proses loading dan } \\
\text { unloading }\end{array}$ & Manual oleh operator \\
\hline & B & Proses Operasional & $\begin{array}{l}\text { Mudah dan otomatis (Cukup } \\
\text { dengan } 1 \text { operator) }\end{array}$ \\
\hline \multirow[t]{3}{*}{3} & \multicolumn{3}{|c|}{ Tuntutan Tersier } \\
\hline & A & Proses Perawatan & Mudah \\
\hline & B & $\begin{array}{l}\text { Sumber Energi } \\
\text { Clamping }\end{array}$ & Sumber Penggerak Pneumatik \\
\hline
\end{tabular}

Berdasarkan daftar tuntutan dan perubahan layout produk saat proses pemesinan yang diharapkan oleh perusahaan untuk produk cylinder head dan cover crankcase agar proses efektif dan efisien seperti terlihat pada gambar 5 .

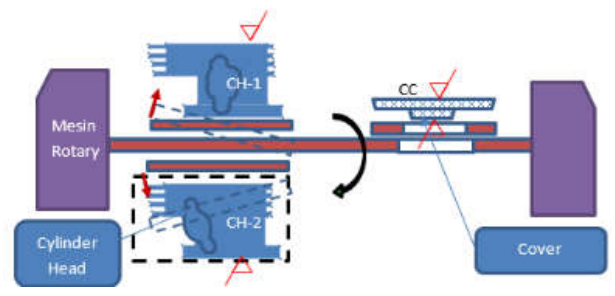

Setelah penyusunan daftar tuntutan dan layout proses ditentukan, selanjutnya ialah tahapan analisis yang meliputi analisa produk, analisa proses pemesinan, analisa mesin yang digunakan, dan analisa operator atau sistem handling [2]. Data penting pada produk cylinder head dan cover crankcase dapat dilihat pada gambar 6 dan gambar 7 .

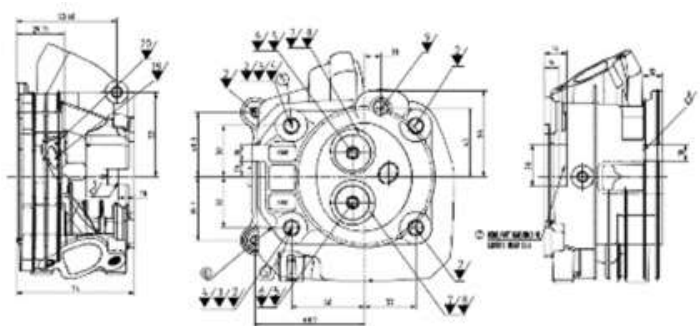

Gambar 6 Analisis produk cylinder head
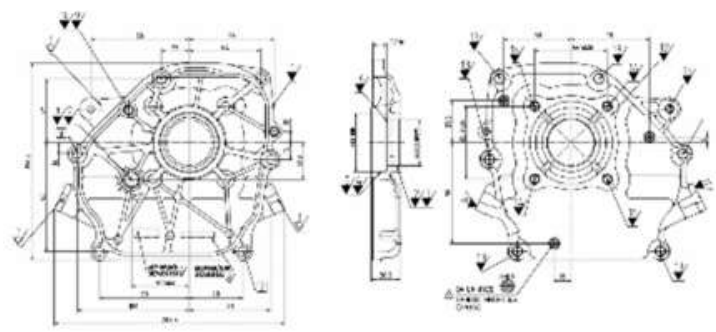

Gambar 7 Analisis produk cover crankcase

Data produk yang penting untuk dikaji adalah datum utama produk, fitur-fitur produk yang mengalami proses pemesinan, hubungan antar dimensi, toleransi ukuran dan toleransi geometrik. Selanjutnya menentukan lokator, tahapan proses pemesinan (operation planning), pencekaman, penumpu, dan rangka fixture [4] dan [5]. Tahap selanjutnya adalah menentukan konsep rancangan fixture dengan menggunakan simbolisasi rancangan seperti pada [6] hal 36-38 yang terlihat pada gambar 8 hingga gambar 10 .

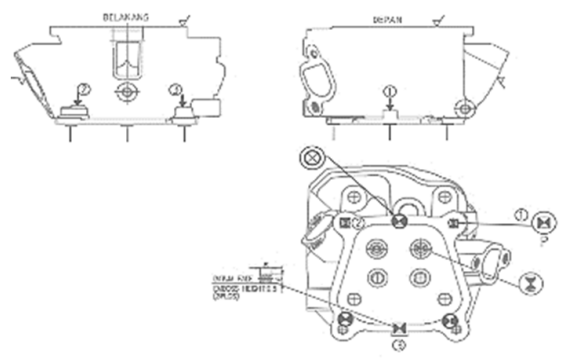

Gambar 8 Simbolisasi posisi-1 cylinder head

Gambar 5 Layout baru fixture untuk produk cover crankcase dan cylinder head

3 Komara, Asep Indra., dkk; Perancangan Ulang Machining Fixture Untuk Produk Cylinder Head Dan Cover Crankcase Tipe 168 

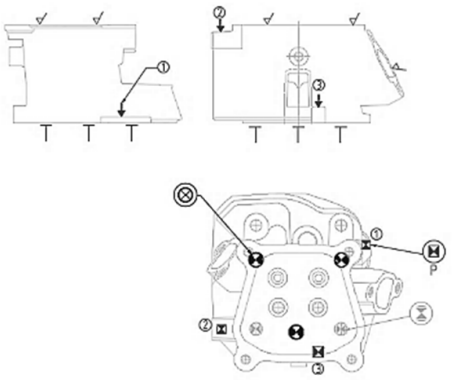

Gambar 9 Simbolisasi posisi-2 cylinder head

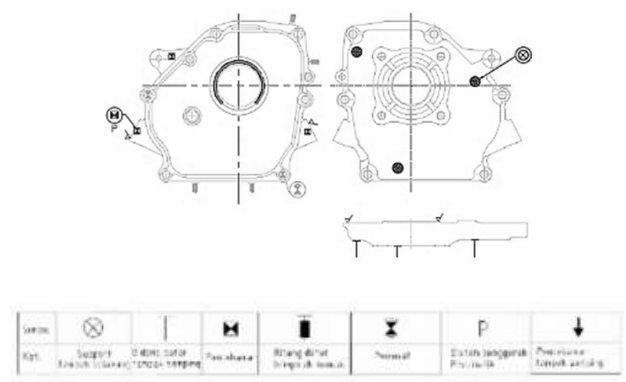

\section{Gambar 10 Simbolisasi cover crankcase}

Simbolisasi rancangan akan mempengaruhi pemilihan komponen fixture. Komponen dipilih dengan mempertimbangkan aspek Design for Manufacture and Assembly (DFMA). Pemilihan komponen diprioritaskan pada komponen standar yang ada dipasaran. Contoh penyusunan alternatif pemilihan komponen dapat dilihat pada tabel 2 .

Tabel 2 Alternatif fungsi bagian

\begin{tabular}{|l|l|l|l|}
\hline Alternatif pemilihan komponen (embodiment) \\
\hline Landasan & Pencekam & $\begin{array}{l}\text { Penump } \\
\text { u }\end{array}$ & Lokator \\
\hline & & \\
Modular Plate & Swing Clamp & $\begin{array}{l}\text { Gripper } \\
\text { Swivel }\end{array}$ & Round Pins \\
\hline A-1 & B-1 & C-1 & D-1 \\
\hline & & & \\
Milling Plate & $\begin{array}{l}\text { Toggle } \\
\text { Clamp }\end{array}$ & $\begin{array}{l}\text { Knurled } \\
\text { Screw }\end{array}$ & $\begin{array}{l}\text { Sraight } \\
\text { Locating } \\
\text { Pin }\end{array}$ \\
\hline A-2 & B-2 & C-2 & D-2 \\
\hline Profil Frame & Link Clamp & $\begin{array}{l}\text { Flat Pin } \\
\text { Shape }\end{array}$ & $\begin{array}{l}\text { Locating } \\
\text { Spring Pin }\end{array}$ \\
\hline A-3 & B-3 & C-3 & D-3 \\
\hline
\end{tabular}

Berbagai alternatif pilihan komponen selanjutnya dikombinasikan menjadi Alternatif Fungsi Kombinasi (AFK) rancangan fixture. AFK konsep rancangan dapat dilihat pada tabel 3 dan tabel 4 berikut.

Tabel 3 Variasi konsep fixture cylinder head

\begin{tabular}{|c|l|c|c|c|}
\hline \multirow{2}{*}{ Sub Fungsi Bagian } & \multicolumn{3}{c|}{ Alternatif Fungsi Bagian } \\
\cline { 3 - 5 } & Alternatif 1 & Alternatif 2 & Alternatif 3 \\
\hline A & Sub Fungsi Landasan & A-1 & A-2 & A-3 \\
\hline B & Sub Fungsi Pencekam & B-1 & B-2 & B-3 \\
\hline C & Sub Fungsi Support & C-1 & C-2 & C-3 \\
\hline D & Sub Fungsi Lokator & D-1 & D-2 & D-3 \\
\hline Alternatif Fungsi Keseluruhan & AFK 1 & AFK 2 & IFK 3 \\
\hline
\end{tabular}

Tabel 4 Variasi konsep fixture cover crankcase

\begin{tabular}{|c|l|c|c|c|}
\hline \multicolumn{2}{|c|}{ Sub Fungsi Bagian } & \multicolumn{3}{c|}{ Alternatif Fungsi Bagian } \\
\cline { 2 - 5 } & Alternatif 1 & Alternatif 2 & Alternatif 3 \\
\hline A & Sub Fungsi Landasan & A-1 & A-2 & A-3 \\
\hline B & Sub Fungsi Pencekam & B-1 & B-2 & B-3 \\
\hline C & Sub Fungsi Support & C-1 & C-2 & C-3 \\
\hline D & Sub Fungsi Lokator & D- & D-2 & D-3 \\
\hline \multicolumn{2}{|c|}{ Alternatif Fungsi Keseluruhan } & AFK 1 & AFK 2 & AFK 3 \\
\hline
\end{tabular}

Penilaian AFK dilakukan berdasarkan aspek teknis dan ekonomis. Berikut ini adalah tabel hasil penilaian alternatif fungsi kombinasi:

Tabel 5 Penilaian AFK rancangan fixture

\begin{tabular}{|c|l|c|c|c|c|c|c|c|}
\hline \multirow{2}{*}{ No } & \multirow{2}{*}{ Kriteria } & \multirow{2}{*}{$\begin{array}{c}\text { Bobot } \\
{[\%]}\end{array}$} & \multicolumn{3}{|c|}{ OP Cylinder Head } & \multicolumn{3}{|c|}{ OP Cover Crankcase } \\
\cline { 3 - 8 } & & AFK1 & AFK2 & AFK3 & AFK1 & AFK2 & AFK3 \\
\hline 1 & Teknis & 70 & $73,8 \%$ & $83,8 \%$ & $77,5 \%$ & $73,8 \%$ & $83,8 \%$ & $77,5 \%$ \\
\hline 2 & Ekonomis & 30 & $90 \%$ & $90 \%$ & $90 \%$ & $90 \%$ & $90 \%$ & $90 \%$ \\
\hline & Persentase & 100 & $78,6 \%$ & $85,6 \%$ & $81,3 \%$ & $78,6 \%$ & $85,6 \%$ & $81,3 \%$ \\
\hline
\end{tabular}

Berdasarkan kedua kriteria tersebut maka fungsi kombinasi yang paling ideal adalah alternatif 2. Rancangan fixture ini terusun atas milling base sebagai fungsi landasan, Gripper Swivel sebagai fungsi support, Swing clamp sebagai fungsi pencekam, dan locating pin straight sebagai fungsi locator. Secara keseluruhan konsep rancangan fixture dapat dilihat pada gambar 11 dibawah ini.

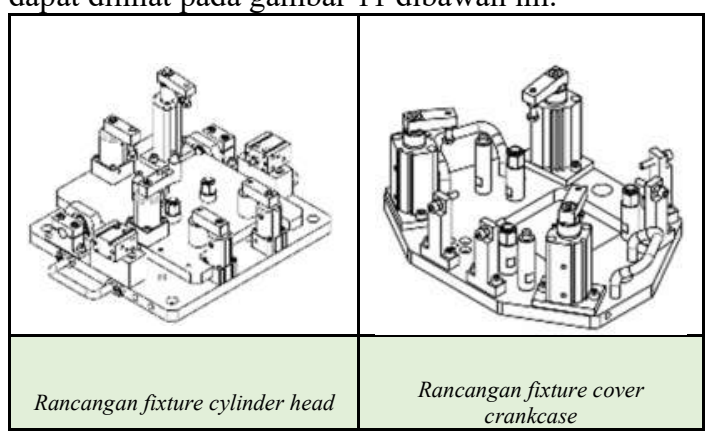

Gambar 11 Konsep rancangan fixture terpilih

4 Komara, Asep Indra., dkk; Perancangan Ulang Machining Fixture Untuk Produk Cylinder Head Dan Cover Crankcase Tipe 168 
Rancangan fixture selanjutnya dirakit dengan komponen rotary table dan dudukan keseluruhan fixture seperti pada gambar 12 berikut.

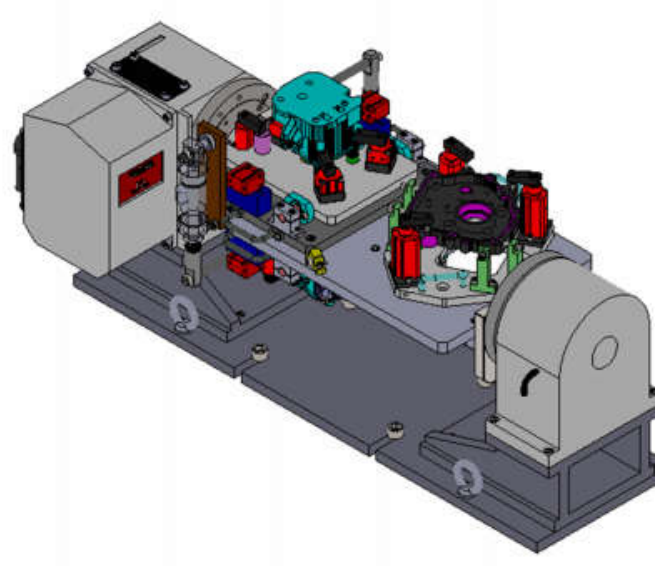
Gambar 12 Rancangan keseluruhan fixture
pada rotary table

Rancangan fixture selanjutnya dievaluasi dan divalidasi berdasarkan aspek teknis dan ekonomis, diantaranya yaitu:

1) Estimasi waktu proses pemesinan produk

2) Analisis gaya pencekaman

3) Analisis sistem clamping

4) Analisis sistem rangka

5) Analisis deformasi produk

6) Estimasi biaya pembuatan

7) Break even point

Berdasar pada kondisi layout fixture hasil rancangan baru seperti terlihat pada gambar 13, selanjutnya dilakukan estimasi waktu proses dengan tujuan untuk mengetahui jumlah produk yang dapat diselesaikan dalam satu kali siklus dan gaya potong yang terjadi untuk menentukan besarnya gaya cekam yang harus diberikan. Perhitungan dilakukan seperti pada [7] hal 173-223.

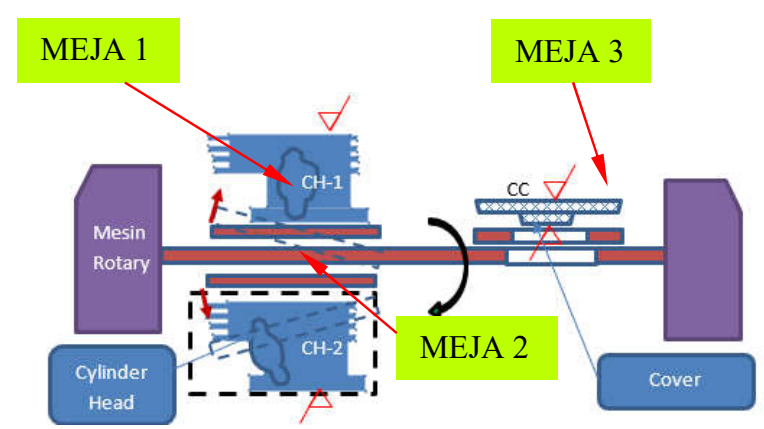

Gambar 13 Kondisi layout fixture
Hasil simulasi kajian waktu dan gaya pemesinan untuk kedua produk dapat dilihat pada tabel 6 berikut.

Tabel 6 Estimasi waktu dan gaya potong

\begin{tabular}{|l|c|c|c|}
\hline \multicolumn{1}{|c|}{ Parameter } & $\begin{array}{c}\text { Fixture } \\
\text { Meja-1 }\end{array}$ & $\begin{array}{c}\text { Fixture } \\
\text { Meja-2 }\end{array}$ & $\begin{array}{c}\text { Fixture } \\
\text { Meja-3 }\end{array}$ \\
\hline Jenis pemesinan & Face milling & Face milling & Face milling \\
\hline $\begin{array}{l}\text { Gaya potong } \\
\text { terbesar }\end{array}$ & $963,56 \mathrm{~N}$ & $985,73 \mathrm{~N}$ & $753,9 \mathrm{~N}$ \\
\hline Waktu proses & \multicolumn{2}{|c|}{$243,37 \mathrm{det}$} & $158,89 \mathrm{det}$ \\
\hline $\begin{array}{l}\text { Waktu proses } \\
\text { tanpa fixture }\end{array}$ & \multicolumn{2}{|c|}{$1019,17 \mathrm{det}$} & $808,83 \mathrm{det}$ \\
\hline
\end{tabular}

Berdasarkan hasil estimasi diatas, dapat disimpulkan bahwa waktu proses dengan menggunakan fixture telah sesuai dengan permintaan customer yang menginginkan waktu masining produk 5 menit per produk.

Setelah diketahui kondisi gaya-gaya yang terjadi saat pemesinan, selanjutnya dirancang sistem pencekaman (clamping) pada fixture. Pemilihan sistem pencekam dilakukan dengan mempertimbangkan besar gaya pemesinan, posisi cutter, posisi pencekam, tumpuan dan standar pneumatic clamp yang tersedia.

Analisis terhadap sistem pencekaman dilakukan untuk memastikan tidak terjadi kegagalan pada proses pemesinan produk. Tegangan dan defleksi batang pencekam dihitung dengan menggunakan persamaan berikut [8]:

$$
\begin{aligned}
& \sigma_{b}=\frac{\mathrm{M}_{b}}{\mathrm{~W}_{b}} \leq \sigma_{i z i n} \\
& \mathrm{M}_{b}=F . l \\
& \mathrm{~W}_{b}=\frac{\mathrm{I}_{x}}{\mathrm{e}} \\
& f=\frac{F . l^{3}}{3 . E . I} \leq f_{i z i n}
\end{aligned}
$$

Gaya yang ditahan oleh batang pencekam adalah sebesar $\mathrm{F}=360 \mathrm{~N}$, dengan ukuran penampang $\mathrm{b}=16, \mathrm{~h}=16$, dan lubang $\varnothing 5$ serta jarak dari tumpuan ke tumpuan sebesar $35 \mathrm{~mm}$, maka tegangan yang terjadi sebesar $26,846 \mathrm{~N} / \mathrm{mm}^{2}$ dan defleksi yang terjadi sebesar $0,0046 \mathrm{~mm}$. Hasil ini dikonfirmasi dengan menggunakan perangkat lunak rekayasa [9] seperti terlihat pada gambar 14 dan gambar 15 dibawah ini. 


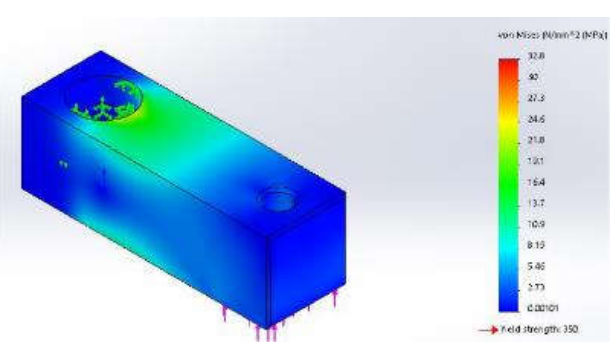

Gambar 14 Simulasi tegangan pada batang pencekam

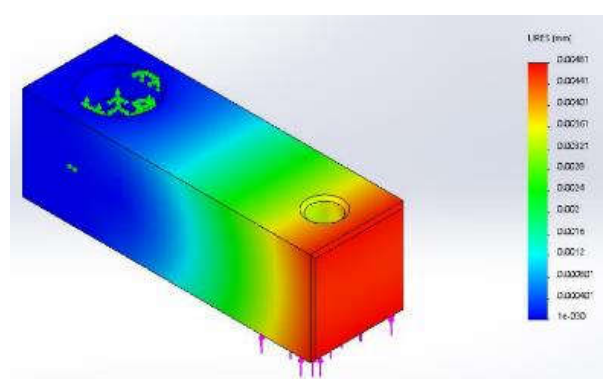

\section{Gambar 15 Simulasi defleksi pada batang pencekam}

Simulasi menunjukkan hasil tegangan yang terjadi sebesar $32,8 \mathrm{~N} / \mathrm{mm}^{2}$ dan defleksi sebesar $0,0048 \mathrm{~mm}$.

Untuk mengetahui pengaruh gaya pencekaman terhadap deformasi pada produk yang akan dimasining, maka dilakukan pula simulasi pada produk. Simulasi dilakukan pada produk cover crankcase yang menerima beban akibat pencekaman sebesar $3 \times 250 \mathrm{~N}$ dan akibat proses pemesinan sebesar 754 N. Defleksi maksimum yang terjadi pada produk sebesar 0,06 mm seperti terlihat pada gambar 16 .

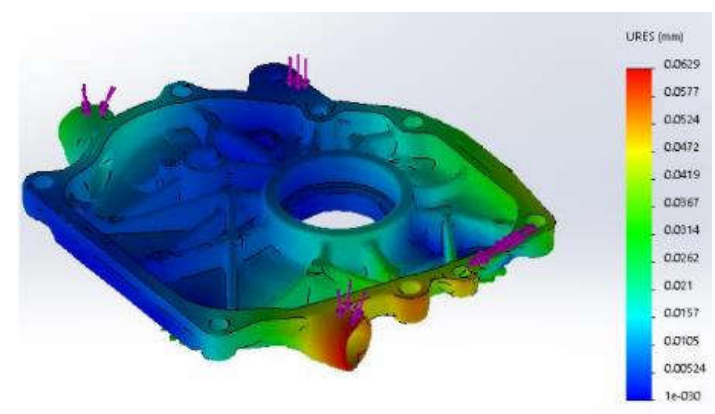

Gambar 16 Simulasi defleksi akibat gaya pemesinan dan gaya cekam pada produk

Selanjutnya simulasi sistem rangka dilakukan untuk meminimalisir terjadinya penyimpangan dimensi akibat dari defleksi pada rangka base plate ketika menahan gaya dari proses pemesinan, gaya berat komponen-komponen serta produk diatasnya. Hasil simulasi menunjukkan bahwa defleksi maksimum yang terjadi sebesar 0,0294 pada proses drilling seperti terlihat pada gambar 17 berikut.

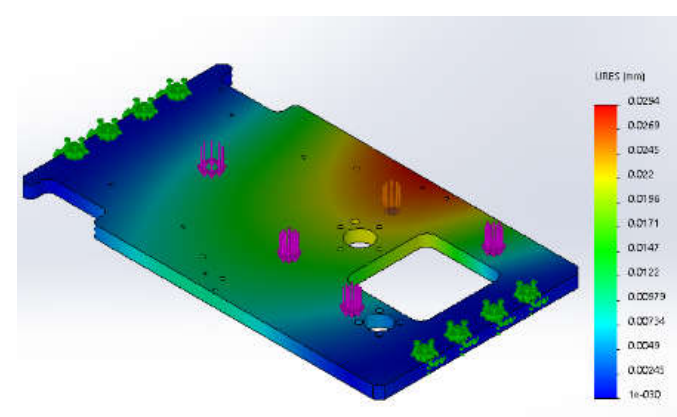

\section{Gambar 17 Simulasi defleksi pada rangka base plate}

Kondisi defleksi hasil simulasi yang dilakukan terhadap rancangan fixture dapat dilihat pada tabel 7 berikut.

Tabel 7 Kondisi hasil simulasi fixture

\begin{tabular}{|c|c|c|c|c|}
\hline \multicolumn{4}{|c|}{ Simulasi Defleksi } & \multirow[b]{2}{*}{ Status } \\
\hline Fitur & $\begin{array}{c}\text { Manual } \\
{[\mathrm{mm}]}\end{array}$ & $\begin{array}{c}\text { Software } \\
{[\mathrm{mm}]}\end{array}$ & $\begin{array}{c}\text { Batas izin } \\
{[\mathrm{mm}]}\end{array}$ & \\
\hline $\begin{array}{l}\text { Batang } \\
\text { pencekam }\end{array}$ & 0,0046 & 0,0048 & 0,03 & Aman \\
\hline Produk & - & 0,06 & 0,1 & Aman \\
\hline $\begin{array}{l}\text { Base } \\
\text { Plate }\end{array}$ & - & 0,029 & 0,03 & Aman \\
\hline
\end{tabular}

Merujuk pada hasil simulasi yang dilakukan, besarnya defleksi pada sistem clamping dan sistem rangka masih masuk dalam batas toleransi fixture yaitu sebesar $0,03 \mathrm{~mm}$. Defleksi pada produk juga masih dalam batas toleransi produk yaitu sebesar 0,1 $\mathrm{mm}$. Sehingga fixture dapat memenuhi tuntutan dari aspek rigiditas.

\section{KESIMPULAN}

Berdasar hasil kajian yang dilakukan pada perancangan ulang Machining Fixture untuk produk Cylinder Head dan Cover Crankcase tipe 168, maka dapat disimpulkan bahwa:

1. Telah dihasilkan rancangan fixture baru yang sesuai dengan spesifikasi yang diharapkan oleh customer.

2. Dimensi fixture baru adalah $1125 \mathrm{~mm} \times 450 \mathrm{~mm}$ x $459 \mathrm{~mm}$ dengan area kerja $340 \mathrm{~mm}$ x $600 \mathrm{~mm}$ dan berat total fixture $190 \mathrm{~kg}$ sesuai dengan mesin yang akan digunakan. 
3. Waktu proses pemesinan menggunakan fixture baru telah terpenuhi yaitu 308,67 detik untuk produk Cylinder Head, dan 224,19 detik untuk Cover Crankcase.

4. Besarnya gaya clamping pada posisi-1 sebesar $0,36 \mathrm{kN}$ (3 buah), posisi-2 sebesar $0,36 \mathrm{kN}$ (3 buah), dan posisi-3 sebesar $0,25 \mathrm{kN}$ (3 buah).

5. Besar defleksi pada batang clamping adalah $0,005 \mathrm{~mm}$, defleksi pada produk sebesar 0,06 $\mathrm{mm}$, dan defleksi pada rangka sebesar $0,029 \mathrm{~mm}$ tidak menyebabkan kegagalan pada hasil proses pemesinan produk.

\section{DAFTAR PUSTAKA}

[1] Komara, A.I., Saepudin., Aplikasi Metoda VDI 2222 Pada Proses Perancangan Welding Fixture Untuk Sambungan Cerobong dengan Teknologi CAD/CAE. Jurnal Ilmiah Teknik Mesin Cylinder, 2014, Vol.1 No.2: 1-8.

[2] Boyes William E., Handbook of Jig and Fixture Design, 2nd Edition, Society of Manufacturing Engineers, 1989.

[3] Carr lane Manufacturing Co., Jig \& Fixture Handbook 3rd Edition, 2016.

[4] Prajapati Rakesh., Fixture Modification of a 5Axis CNC Machine (Makino), International Journal of Engineering and Advanced
Technology (IJEAT), Volume-7, Issue-2, December 2017., pp 16-23. doi: 10.13140/RG.2.2.21127.70565.

[5] Basha V.R., Salunke J.J., An Advanced Exploration on Fixture Design, International Journal of Engineering Research and Applications, Vol.5, Issue 6, (Part-3), June 2015, pp.30-33

[6] Matuszewski Heinrich., Handbuch Vorrichtungen: Konstruktion und Einsatz, Friedr. Vieweg \& Sohn, Braunschweig/wiesbaden, 1986.

[7] Tschätsch Heinz., Applied Machining Technology, Springer Dordrecht Heidelberg London New York, 2009

[8] Wittel Herbert., Muhs Dieter., Jananasch Dieter., Vossiek Joachim., Roloff/Matek Maschinenelemente., Springer Vieweg, 2013.

[9] Akin J. Ed., Finite Element Analysis Concepts via SolidWorks, World Scientific, 2009.

[10]Prassetiyo Hendro., Rancangan Jig dan Fixture Pembuatan Produk Cover On-Off. Jurnal Teknoin Vol. 22, No 5, 5 Desember 2016: pp 350-360, doi.org/10.20885/v22i5.7461

[11]Santosa Aa., Perancangan Jig Dan Fixture Sistem Pneumatik Untuk Proses Pemasangan Bearing Dan Absorber Pada Velg Rear Wheel., Jurnal Ilmu dan Aplikasi Teknik, Vol.2, No.1, Januari 2017: pp 1-12. 